\title{
Hans-Werner Wahl, Clemens Tesch-Romer and Andreas Hoff (eds.) (2007). New Dynamics in Old Age: Individual, Environmental and Societal Perspectives. New York: Baywood Publishing Co., 400 pp. ISBN 0-89503-322-4 (hpk)
}

\section{REVIEWED BY SARA ARBER ${ }^{1}$}

New Dynamics in Old Age represents an outstanding edited collection of scholarship on aging for the twenty-first century. The key aim is to critically examine changes that have affected aging since the Second World War while looking ahead to the changes on the horizon in terms of older people's everyday lives and policies pertaining to older people. A key thesis is that the post-war consensus of welfare policies supporting older people has been broken down by profound societal changes, which through globalisation have affected all western societies to different degrees. The focus is on continuity and change related to aging both at an individual level and as a social process. This theoretically sophisticated set of essays provides evidence that the very concept of aging has taken on a completely new form over recent decades. A key thread is to examine the dynamics of societal discourses about aging, for example relating to older people as a "burden" and "successful aging", "new aging" and "new agers".

The editors have assembled 20 chapters by a galaxy of leading scholars and researchers within the field of aging from the US and northwest Europe. The focus is primarily western research on aging, drawing on disciplines from across social gerontology, including from sociology, social psychology, and social policy. The introductory section includes a notable chapter by Kenneth Manton and XiLuang Gu on changes in physical and mental functioning in old age, illustrating the major reduc-

1 Sara Arber, Centre for Research on Ageing and Gender (CRAG), Department of Sociology, University of Surrey, Guildford, Surrey, UK. 
tions in cognitive decline and physical disability over the last 20 years, which have critical demographic and social implications, and a chapter by Christine Fry on the social construction of age. With so many outstanding authors, this review will only mention a selection of the chapters.

The term "environment" is used as an organising thread throughout the book, combining social and physical, as well as micro-level and macro-levels of analysis.

The book is organised around five areas, which in each case illustrate the dynamics of change. The first section on the social environment, focuses particularly on cohort effects in social relations, family relations and elders as care receivers. Andreas Hoff and Clemens Tesch-Romer explore changes in the nature of exchanges within networks of families and kin, particularly in terms of support and conflict, as well as the ways in which notions about the family have changed over time. Steven Zarit and Elizabeth Braungart focus on elderly people as care receivers emphasising the lack of voice given in gerontological research to care receivers, and examine ways of increasing their autonomy and control.

The second section examines the home environment with an emphasis on housing and quality of life, relocation, and urban aging issues. Frank Oswald and Graham Rowles review research on a range of types of decisions about relocation in later life, whether to sheltered housing or other caring contexts, and as migrants to the sunbelt of Florida or Spain. An insightful chapter is provided by Tom Scharf and colleagues who analyse "aging in a difficult place", focusing on older people living in deprived urban areas.

The outdoor environment is the focus of the third section, providing a consideration of out-of-home activity patterns, car-driving behaviours and the leisure world of aging. Karlene Ball and colleagues remind us of the importance of continued mobility as critical for maintaining social contacts, independent functioning and quality of life. They examine the ways that new technologies have the potential to help older adults extend their safe driving years. Franz Kolland reviews existing literature on leisure research, providing an overview of concepts of leisure, and the position of leisure within different theoretical approaches to social geron- 
tology, as well as leisure as a key aspect of self-actualisation and selfdevelopment.

The fourth section examines new and persistent dynamics regarding the technological environment, including chapters on the role of the Internet and the potential of technology for improving aging outcomes. Since age-related declines and chronic conditions have the potential to severely limit our ability to do everyday tasks, William Mann and Sumi Helal focus on a new generation of assistive devices labelled "smart technology". A key issue is to what extent such assistive technologies have the potential to facilitate older people remaining independent for longer, and significantly reduce the burden of care giving for family members.

The section on the societal environment focuses on global aging and the new politics of old age, as well as older persons as market consumers. Chris Phillipson examines how globalization is a transformative force which has reshaped the boundaries through which old age is experienced. He provides an insightful review of historical developments in the social position of older people, outlines the emergence of critical gerontology, and examines new policy questions arising from the impact of globalization and the increasing privatisation of welfare on the lives of older people. Alan Walker addresses the political paradox of old age, namely that large and growing numbers of older people coexist with a lack of political influence of older people, arguing that "grey power is a myth".

The final section of the book on "new challenges" includes a chapter by Svein Olav Daatland and Andreas Motel-Klingebiel, which argues for the importance of comparative cross-national research on aging. They clearly outline how cross-national studies can be used to disentangle the structuralist position, which assumes that similar macro-characteristics will produce similar outcomes for individuals in different societies, from the culturalist position, which assumes that social/cultural values may modify the effects of a given policy change and lead to different outcomes.

While the thematic organisation of New Dynamics in Old Age provides a coherent substantive division of research literatures on aging, the result is that little systematic attention is paid to diversity and inequality within older populations, particularly relating to gender, class and mate- 
rial resources, as well as race, ethnicity and sexuality. A key issue should be to what extent these inequalities are increasing over time, and the policy implications of growing inequalities among the older population.

Overall, the book provides very comprehensive and up-to-date reviews of relevant literature and debates within a wide range of areas that are central to an understanding of older people in the twenty-first century. New Dynamics in Old Age will be an essential resource for researchers and a valuable teaching text for students of social gerontology. 